\title{
Learners' Perceptions of Assessment Strategies in Higher Education
}

\section{Clay Hutama Basera}

Great Zimbabwe University Munhumutapa School of Commerce Department of Management Studies Masvingo, Zimbabwe.

Email:baseraclay@gmail.com

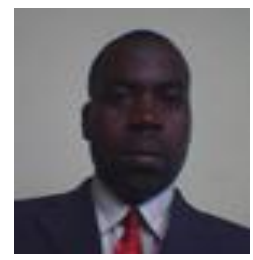

\begin{abstract}
The study sought to establish learner perceptions about assessment strategies in higher education. This was against the backdrop of an emerging trend in the field of assessment that has resulted in different perceptions of learners with respect of their effectiveness in higher education learning. The study in particular endeavored to determine the perceptions of learners in relation to formative and summative assessment, as predominantly adopted assessment strategies in higher education. Forty six learners doing research methods were conveniently chosen to represent the target population and were served with self-administered questionnaires. The instrument used enabled the researcher to obtain quality data as respondents were given ample time to complete the questionnaire with limited pressure. The results were indicative of the fact that learners perceived formative assessment as a critical ingredient for effective learning in higher education. Formative assessment methods such as group presentations and other forms of collaborative learning were also perceived to be critical in higher education learning. Respondents also indicated that they perceived summative assessment as playing an augmenting role. Thus the two assessment approaches are perceived to be strategically important in enhancing effective learning in higher education.
\end{abstract}

Keywords: Assessment, Diagnostic assessment, Formative assessment, Summative assessment, Learner and perception.

Citation | Clay Hutama Basera (2019). Learners' Perceptions of Assessment Strategies in Higher Education. Journal of Education and e-Learning Research, 6(2): 76-81.

History:

Received: 16 January 2019

Revised: 20 February 2019

Accepted: 24 April 2019

Accepted: 24 April 2019

Licensed: This work is licensed under a Creative Commons

Attribution 3.0 License (c)

Publisher: Asian Online Journal Publishing Group
Funding: This study received no specific financial support.

Competing Interests: The author declares that there are no conflicts of interests regarding the publication of this paper.

Transparency: The author confirms that the manuscript is an honest, accurate, and transparent account of the study was reported; that no vital features of the study have been omitted; and that any discrepancies from the study as planned have been explained.

Ethical: This study follows all ethical practices during writing.

\section{Contents}

1. Introduction 77

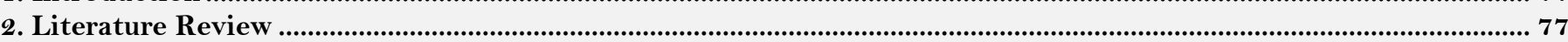

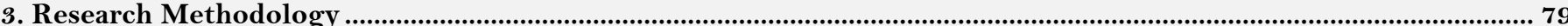

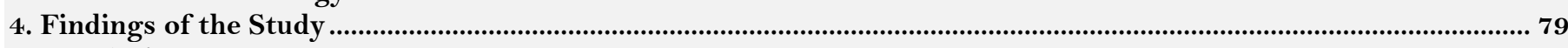

5. Conclusions ...s.usus 81

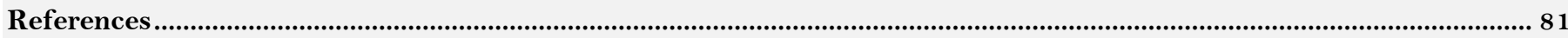




\section{Contribution of this paper to the literature}

Although learner assessment has been studied on a number of platforms, it is prudent to realize that this study was done in Zimbabwe and that the study findings will contribute to the existing body of knowledge.

\section{Introduction}

When there is mention of teaching in higher education, the most often talked about issue focuses on assessment which has been at the heart of higher education learning and key facets normally discussed relate to course work in terms of assignments (both individual and or collaborative), group work, presentations as well as in-class tests which form the bases for formative assessment and the end of semester examinations which form summative assessment. An array of assessment strategies applied in higher education have increased in recent decades. Sambell et al. (1997) claim that new approaches of assessment have enhanced the prevailing traditional methods of evaluation and these include multiple-choice and use of essay type examination questions. Trends in higher education assessment show that the use portfolios, self and peer assessment, simulations and other innovative strategies are becoming more apparent in higher educational settings. These, according to Struyven et al. (2005) constitute the optional assessment criteria in higher education. Students' perceptions about these old and new approaches to assessment are at the heart of this research undertaking. Assessment is vital in order to afford learners an opportunity to reflect on their performance and to establish the extent to which they have progressed towards achieving their targets. Feedback is vital as it enables students to realise what they have done extremely well and also to identify areas that require attention as the means through which the learner can make necessary adjustment. Gibbs and Simpson (2004) claim that the thrust of the Quality Assurance Agency (QAA) has been to enhance the quality of the students' learning and their assessment in higher education. Thus when universities and other higher learning institutions engage particular instructional strategies they will in fact be trying to align learning outcomes with certain assessment methodologies.

Assessment is vitally important in higher education because it stimulates learners' attitudes and behaviours towards learning. It gives them the necessary feedback on their strengths and weaknesses and it offers them insights on how they might improve in future. It also affords the instructor an opportunity to examine the effectiveness of the assessment strategies used and to evaluate the extent to which learners have understood certain concepts learnt and besides it allows the lecturer to have a self-appraisal of his/her competences. Instructors also have the privileges to check on whether the learning goals are being attained (Zou, 2008). In other words the major objective of assessment is premised on boosting student learning and development and rather than merely according grades. Morgan and O'Reilly (1999) contend that assessment is vital for enabling students to enhance the quality of their learning and the concept of grading should play second fiddle. Hornby (2005) in Scotland found out that the pace of change in assessment practices in that country could not match that of the higher education sector. A number of key variables have affected the effectiveness of assessment in higher education some which include the unbalanced growth of student numbers in relation to available resources, instructors are overwhelmed by work overloads, pace of formative assessment has slackened and is often carried out poorly and not meaningful; learning outcomes are often assessed several times with no rationale. Also, mechanisms that are in place are poor for enhancing co-ordination across modules.

\section{Literature Review}

\subsection{Assessment}

Assessment entails all the activities undertaken by instructors to gather data on learners. Thus instructors collect data during the learning process about the effectiveness of their deliveries and their learners' ability to grasp learnt material (Hanna and Dettmer, 2004). These activities employ a myriad of approaches to assessment such as: pre-tests, homework, group presentations, observations, fieldwork and yearly examinations. Pieces of data from these forms of assessment enable instructors to evaluate the learner's performance. Assessment takes three broad categories namely diagnostic, formative and summative assessment.

\subsection{Diagnostic assessment}

This is a diagnostic tool for assessment that an instructor uses to identify his/her learners' current level of understanding of a particular subject or topic before teaching takes place. This approach to assessing learners is vital in order to dispel misconceptions beforehand as well as giving the instructor a platform for proper planning before entering into learning venues regarding what to teach and the methods to engage. Some common approaches include the use of pre-tests, self-assessments and brief learner interview. However this assessment strategy is no popular in higher education which deals with learners with diverse learning backgrounds and learning experiences.

\subsection{Formative assessment}

(Harvey, 1998) idealises the concept of assessment satirically when he says "When the cook tastes the soup it is formative evaluation; when the dinner guest tastes the soup, it is summative evaluation." A number of definitions have been coined to refer to formative evaluation. Black (1999) defines formative assessment as "the short term collection and use of evidence to guide learning". Higgins et al. (2010) define formative assessment as "work that a student carries out during a module, for which they get feedback to improve their learning, whether marked or not". Baume (1998) underscores that formative assessment is that which occurs during the learning period and it is meant to provide feedback to inform further learner development. He compares this to summative assessment in which the aim is to sum up the learners' achievements over a learning period. Formative assessment offers feedback to learners and it is therefore critical for ensuring sound learning outcomes and on the other hand, summative assessment overlooks real learning as it is premised on grading or performance ranking (Boud, 1995). Thus in light of the above, the Open University (2008) views formative assessment as "assessment for learning, whereas 
summative assessment is assessment of learning”. Wisdom (2006) prefers to describe formative assessment as a journey, rather that it being an outcome. Gibbs (1998) posit that a constant tension exist the two assessment methodologies and argues each of the two may work with differing level of effectiveness from one institution to the other.

Yorke (2005) claims that "formative assessment can assume a variety of forms; it may be used as a component of the final mark or just for ordinary evaluation. It may be deemed formal or informal in nature. The distinction between formative and summative assessment may sound straightforward but even experienced lecturers can get confused. The distinction between the two can be blurred because some assignments are both; students can learn from feedback but also receive a grade”. Research however argues that the two forms of assessment are interlinked as Ramsden (1992) views the two as existing in a continuum rather than being antagonistic but rather a situation where formative assessment leads into summative assessment (Brown, 1999). There are a number of formative assessment criteria that instructors in higher education may adopt some which are discussed below:

\subsection{Question and Answer during Lectures}

This is one of the most prevalent traditional methods of formative assessment commonly used by instructors in higher education and this approach is almost instinctive for lecturers. This assessment strategy is advantageous in the sense that its feedback is immediate for both the learners and the instructor although it is believed to have little motivational effect because it is ephemeral- implying that it lasts for short period of time because it does not keep a written record for future reference.

\subsection{Short In-Class Tests}

These are continuous assessment exercises that are given to learners as a way of appraising the extent to which they have effectively understood concepts in topic or chapter covered. Such tests enable the instructor to assess the learners' preparedness for the summative assessment. Although in-class tests are not mandatory or informal, they are recorded and depending on the interests of the instructors can be recorded and contribute towards a learner's final grade at the end of the course.

\subsection{Homework Exercises}

Homework exercises vary in purpose, design and complexity. A student may be assigned to work on a particular topic for the purpose of leading others in a class discussion. Thus learners make good use of such assignments when they realise their potential benefits to their learning.

\subsection{Assignments}

The term assignment refers to an array of different tasks, some which may be assigned to a group or individuals. Assignments may take the form of individual research assignments for a group project. It is a useful formative assessment strategy which is normally applied in conjunction with homework. The strategy makes use of the library and internet research for learners to do the assigned tasks correctly. The approach however has challenges particularly when the instructor wants to establish the extent to which an individual learner has contributed to the whole. The instructor may assume that the work jointly and severally belongs to the entire group and yet others may not have participated in undertaking the group work. The instructor will not make an objective assessment which may affect the outcomes of summative assessment since formative may be used for learners' final grading.

\subsection{Student Portfolios}

A portfolio is a "systematic collection of a student's work and related material that depicts a student's activities, accomplishments, and achievements in one or more school subjects. The collection should include evidence of student reflection and self-evaluation, guidelines for selecting the portfolio contents, and criteria for judging the quality of the work. The goal is to help students assemble portfolios that illustrate their talents, represent their writing capabilities, and tell their stories of school achievement" (Venn, 2000). A number of benefits have been found to accrue to students as a result of using this approach to assessment, some which are that learners have the opportunity have an objective self-evaluation and make a personal reflection in their learning. Portfolios provide practical evidence on the learner's work.

\subsection{Summative Assessment}

A high-stakes method of assessment that is used to judge the learner's extent of grasping learnt materials and the effectiveness of the instructional methods engaged during the learning process. Unlike diagnostic and formative assessments which are done prior and during the learning process, Summative assessment is a post learning assessment tool that is employed after actual learning has been done. Although there might still be some form of learning, it will be somehow informal through projects and other practical assignments. Summative assessment takes a number of approaches some of which include end of semester examinations, projects, term papers, portfolios and others.

\subsection{Perception}

Perception entails a psychological process by which sensations are internally driven to reflect the meaning of the real world. Rathus (2007) defines perception as "the process by which sensations are organized into an inner representation of the world". Dorman and Knightley (2006) claim that learners hold distinct perceptions on a number evaluative approaches mostly adopted as assessment tools. Students are keen know that the process of assessment is objectively carried out as they perceive fairness of assessment as important to the outcomes of their learning. Learners are happy and motivated when they perceive that there is congruence between classroom learning and relevance to what real happens in the world. Cavanagh et al. (2005) identify five attributes that 
learners perceive to constitute classroom assessment such as compatibility with planned learning, genuineness, learner consultation, openness, and acceptable to learner diversity. Ideally, students perceive assessment as genuine when the following conditions are met: (1) that assessment tasks link directly with the learning goals, objectives, and the overall learning program; (2) that assessment tasks depict real-life circumstances that are tangible in the learning of students; (3) that consultations with students should be made so that they are fully appraised about the optional assessment strategies being employed; (4) that the aspect to be assessed are clearly conveyed; and (5) that all learners stand an equal chance of completing assessment tasks.

\section{Research Methodology}

The study was carried out at Great Zimbabwe University's Mashava campus; the study adopted an exploratory research design. The target population was 68 second year students in the Munhumutapa School of Commerce's management studies department who were doing a research methods module as part of their course requirements. As part of their fieldwork the group was chosen to participate in the data collection exercise. A sample size of 46 conveniently selected students who happened to enter into the learning venue before the start of the lesson were given a self-administered questionnaire to fill in during their spare time. The semi- structured questionnaire was initially pretested with 5 second year students from the department of accounting who were not included in the final sample. After dropping the survey instrument the researcher gave a brief explanation on the general instructions as well as the ethical issues to be observed when completing the questionnaire. The researcher adopted this method because of its flexibility. Besides it offered the respondents an opportunity to respond to the questions with no pressure such that they gave genuine responses. The completed questionnaires were collected a week later in preparation for data analysis. Data was analyzed using simple descriptive statistics as reflected below.

\section{Findings of the Study \\ 4.1. Demographic Profiles of Respondents by Age and Gender}

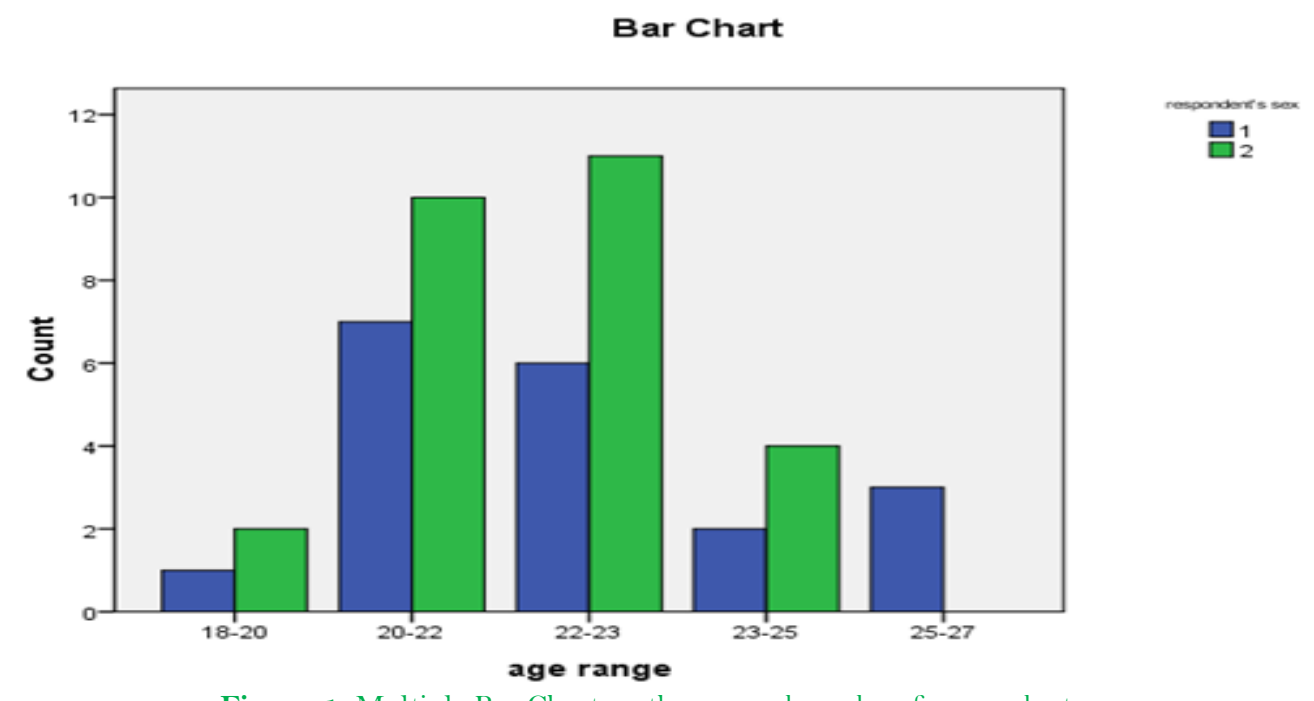

Source: Fieldwork.

Figure-1. Multiple Bar Chart on the age and gender of respondents.

The above multiple bar charts depict the composition of study participants on the basis of age and gender. The data in the diagram above shows that participant ages ranged from 18 years to 27 years and that the bulk of the study participants were from the 20-22 and 22-23 age groups. The 20-22 age range had 7 male and 10 female participants while the 22-23 class had 6 male and 11 female respondents. This shows that the students in second year in the school are mostly in that age category. In terms of participation by gender there were more females compared to the females, an aspect which may reflect that there are more male students compared to their female counterparts.

Table-1. Descriptive statistics on learners' general perceptions about assessment.

\begin{tabular}{|c|c|c|c|c|c|c|c|}
\hline \multirow{2}{*}{$\begin{array}{l}\text { Statements on general } \\
\text { perceptions about } \\
\text { assessment }\end{array}$} & \multirow{2}{*}{$\frac{\mathrm{N}}{\text { Statistic }}$} & \multirow{2}{*}{$\begin{array}{c}\text { Mean } \\
\text { Statistic }\end{array}$} & \multirow{2}{*}{$\begin{array}{c}\text { Std. Deviation } \\
\text { Statistic }\end{array}$} & \multicolumn{2}{|c|}{ Skewness } & \multicolumn{2}{|c|}{ Kurtosis } \\
\hline & & & & Statistic & Std. Error & Statistic & Std. Error \\
\hline $\begin{array}{l}\text { assessment on student } \\
\text { learning }\end{array}$ & 46 & 1.54 & 0.887 & 2.259 & 0.35 & 5.755 & 0.688 \\
\hline $\begin{array}{l}\text { assessment motivates to } \\
\text { study further }\end{array}$ & 46 & 1.54 & 0.585 & 0.52 & 0.35 & -0.631 & 0.688 \\
\hline $\begin{array}{l}\text { tests measure } \\
\text { understanding of } \\
\text { concepts }\end{array}$ & 46 & 2 & 0.943 & 1.497 & 0.35 & 3.088 & 0.688 \\
\hline $\begin{array}{l}\text { tests a must in every } \\
\text { module done }\end{array}$ & 46 & 2.52 & 1.206 & 0.304 & 0.35 & -1.008 & 0.688 \\
\hline $\begin{array}{l}\text { tests give pressure to } \\
\text { students }\end{array}$ & 46 & 2.85 & 1.398 & 0.232 & 0.35 & -1.233 & 0.688 \\
\hline Valid N (listwise) & 46 & & & & & & \\
\hline
\end{tabular}

Source: Fieldwork.

The Table 1 gives a summary of responses that learners gave in relation to their perceptions about assessment. Respondents generally agreed that assessment is an important component of their learning process. This is 
evidenced by a mean response rate of 1.54 signifying that most of the answers that respondents gave ranged from strongly agree to agree. This indicates that assessment is generally perceived as an integral part of student learning. The respondents also indicated that they agreed that assessment motivates learners to study further because it gives them chances to reflect on their performances through feedback. This is supported by a mean response value of 1.54 . This value signifies that respondents perceive assessment as being capable of motivating learners to achieve in their learning outcomes. The standard deviation value of 0.585 signifies that there was less variability in the overall responses that were given by the study participants.

The results are supported by Zacharis (2010) who opines that "assessment and feedback drive learning through motivation”. Solomon (1983) claims that students' experience every time they carry out a particular assessment task and the degree to which they achieve those assigned tasks and the related feedback, determine the amount of effort learners will invest. Respondents however were neutral about on whether tests sought to measure how well taught and learnt concepts would have been and that they should be done in every module. The mean response rate from the subjects was 2.52 showing that respondents could neither agree nor disagree on what they perceived as the role of tests. The researcher also wanted to establish if formative assessment is the better assessment tool and the respondents were somehow in agreement that indeed continuous assessment was vital as reflected by a mean response value of 2.35 and a standard deviation of 1.215. The respondents generally agree that continuous assessment is important for enhancing learner outcomes. Ramsden (1992) claims that the feedback function of formative assessment, has a strong bearing on learner motivation. He argues that formative assessment fosters interest, commitment and intellectual challenge amongst higher education learners thereby giving academic independence and responsibility.

\subsection{Learners' Perceptions about Written and Group Assessments}

Assignments are also common elements of assessment in higher education as they are often used as part of course work. Writing of assignments is also an important part of continuous assessment which is commonly practiced in higher and tertiary education in Zimbabwe. These assignments may either be individual or group based.

Table-2. Descriptive statistics on learners' perceptions about written and group assessments.

\begin{tabular}{|c|c|c|c|c|c|c|c|}
\hline \multirow{2}{*}{$\begin{array}{l}\text { Statements about written } \\
\text { and group assignments }\end{array}$} & \multirow{2}{*}{$\frac{\mathrm{N}}{\text { Statistic }}$} & \multirow{2}{*}{$\begin{array}{c}\text { Mean } \\
\text { Statistic }\end{array}$} & \multirow{2}{*}{$\begin{array}{c}\text { Std. Deviation } \\
\text { Statistic } \\
\end{array}$} & \multicolumn{2}{|c|}{ Skewness } & \multicolumn{2}{|c|}{ Kurtosis } \\
\hline & & & & Statistic & Std. Error & Statistic & Std. Error \\
\hline $\begin{array}{l}\text { continuous assessment is } \\
\text { best assessment tool }\end{array}$ & 46 & 2.35 & 1.215 & 0.683 & 0.35 & -0.441 & 0.688 \\
\hline $\begin{array}{l}\text { group presentations offer } \\
\text { opportunity to showcase } \\
\text { potential }\end{array}$ & 46 & 1.54 & 0.936 & 2.419 & 0.35 & 6.64 & 0.688 \\
\hline $\begin{array}{l}\text { give opportunity to interact } \\
\text { and learn more }\end{array}$ & 46 & 1.57 & 0.583 & 0.438 & 0.35 & -0.685 & 0.688 \\
\hline $\begin{array}{l}\text { course work important for } \\
\text { students }\end{array}$ & 46 & 1.72 & 1.089 & 1.679 & 0.35 & 2.297 & 0.688 \\
\hline Valid N (listwise) & 46 & & & & & & \\
\hline
\end{tabular}

Source: Fieldwork.

In Table 2, from the 46 respondents the average response indicated that they agreed that continuous assessment is necessary for assessing learners in higher and tertiary education institutions. This is reflected by a mean response of 2.35 on the 5 - point likert scale, showing that the subjects agree that continuous assessment through written assignments are vital assessment tools. A smaller value of the standard deviation of 1.215 signifies that the answers that were given by the study participants generally pointed toward one direction. The general distribution is positively skewed as reflected by 0.683. Group presentations appear to be a favourite strategy for assessing learners. Respondents have indicated that they enjoy group work as indicated by an average response of 1.54. They agreed that group work awards them the opportunities to showcase their potentials to their peers and that the strategy enables them to interact, an aspect that enhances their learning socially and intellectually. The overall mean response was 1.57 depicting that respondents are in agreement that group work is a vital optional assessment strategy in higher and tertiary education and that it is imperative for enhancing learner outcomes. From instructor view point formative assessment may not be the right prescription for learners. In respect of the higher education dynamics where massification has become the order of the day, the quality of feedback is compromised. Thus massification results in more marking time, yet this result in undesirable amounts of feedback (Falchikov, 1995). This is strongly supported by Gibbs (1998) who contends that giving feedback may be expensive and consumes more and might not automatically help the learners to achieve their learning outcomes. Sometimes it may de-motivate or be useless if ambiguous or too brief.

\subsection{Perceptions about Summative Assessment}

The respondents were asked to give their opinions on their perceptions about summative assessment and almost every respondent alluded to the fact that assessing students at the end of the learning period is fundamental as it enables the learners to get some grading which show how much understanding they will have gained after undergoing a learning process. One respondent had to put it this way that "it is relevant because it gives the student a chance to evaluate his/her level of understanding in their learning process". While some indicated the necessity for summative assessment, they had sentiments that the final examination mark should not carry more weighting since it is done within a short period of time. Some suggested that it should be balanced with that of continuous assessment. Some also indicated that formative assessment does not give a genuine assessment of learners since it may be compromised by a number of factors. During group work assignment some members may not participate, others may copy from others and any other forms of student misconduct that may defile genuine and objective formative assessment. 


\section{Conclusions}

Assessment, in higher education is aimed at churning out high calibre students "who are 'deep' rather than 'surface' learners, highly motivated, equipped with a range of transferable skills, active and reactive participants in the learning process" (Zacharis, 2010). From the study findings it is clear that the roles of both continuous assessment and summative assessment are indispensible. The availability of both assessment methods are fundamental in enhancing successful learning outcomes for students and higher education learners perceive both assessment types as inseparable if higher education institutions are to effectively achieve the goals of learning. While each assessment method has its strengths and challenges, combing the two certainly brings forth better fortunes that enable the institutions to achieve successful learner outcomes.

\section{References}

Baume, D., 1998. Marking and giving feedback, practice guide 4. Milton Keynes: Open University.

Black, P., 1999. Assessment, learning theories and testing systems. In Murphy, P. (Ed.), Learners, Learning and Assessment. London: Paul Chapman. pp: 118-134.

Boud, D., 1995. Assessment and learning. In Knight, P. (Ed.), Assessment for learning in higher education. London: Kogan Page. pp: 35-48.

Brown, S., 1999. Institutional strategies for assessment. In Brown, S. \& Glasner, A. (Eds.), Assessment matters in higher education: Choosing and using diverse approaches. Buckingham: Society for Research into Higher Education and Open University Press. pp: 3-13.

Cavanagh, R., B. Waldrip, J. Romanoski and J. Dorman, 2005. Measuring student perceptions of classroom assessment. Paper Presented at the Annual Conference of the Australian Association for Research in Education, Sydney.

Dorman, J.P. and W.M. Knightley, 2006. Development and validation of an instrument to assess secondary school students' perceptions of assessment tasks. Educational Studies, 32(1): 47-58.Available at: https://doi.org/10.1080/03055690500415951.

Falchikov, N., 1995. Peer feedback marking: Developing peer assessment. Innovations in Education and Training International, 32(2): 175187.Available at: https://doi.org/10.1080/1355800950320212.

Gibbs, G., 1998. Marking and giving feedback in open university centre for higher education practice (Ed.), Teaching in higher education: Theory and evidence. Milton Keynes: Open University. pp: 3-37.

Gibbs, G. and C. Simpson, 2004. Conditions under which assessment supports students' learning. Learning and Teaching in Higher Education, 1: 3-31.

Hanna, G.S. and P.A. Dettmer, 2004. Assessment for effective teaching: Using context-adaptive planning. Boston, MA: Pearson A\&B.

Harvey, L., 1998. An assessment of past and current approaches to quality in higher education. Australian Journal of Education, 42(3): 237255.Available at: https://doi.org/10.1177/000494419804200303.

Higgins, G., R.L. Spencer and R. Kane, 2010. A systematic review of the experiences and perceptions of the newly qualified nurse in the United Kingdom. Nurse Education Today, 30(6): 499-508.Available at: https://doi.org/10.1016/j.nedt.2009.10.017.

Hornby, W., 2005. Dogs, stars, roll royces and old double-decker buses: Efficiency and effectiveness in assessment. In Quality Assurance Agency Scotland (Ed.), Reflections on assessment. Mansfield: Quality Assurance Agency, 1:15-28.

Morgan, C. and M. O’Reilly, 1999. Assessing open and distance learners. London: Kogan Page.

Open University, 2008. Assessment and course design, Learning and teaching guides from IET series. Milton Keynes: Open Univer sity.

Ramsden, P., 1992. Learning to teach in higher education. London: Routledge.

Rathus, S.A., 2007. Psychology. Concepts and connections. 8th Edn., Australia: Thomson Wadworth.

Sambell, K., S. Brown and L. McDowell, 1997. " But is it fair?": An exploratory study of student perceptions of the consequential validity of assessment. Studies in Educational Evaluation, 23(4): 349-371.

Solomon, J., 1983. Messy, contradictory and obstinately persistent: A study of children's out-of-school ideas about energy. School Science Review, 65(231): 225-229.

Struyven, K., F. Dochy and S. Janssens, 2005. Students' perceptions about evaluation and assessment in higher education: A review. Assessment \& Evaluation in Higher Education, 30(4): 325-341.Available at: https://doi.org/10.1080/02602930500099102.

Venn, J.J., 2000. Assessing students with special needs. 2nd Edn., Upper Saddle River, NJ: Merrill.

Wisdom, J., 2006. Developing creativity in higher education: An imaginative curriculum. London: Routledge. pp: $183-196$.

Yorke, M., 2005. Formative assessment and student success. In Quality Assurance Agency. Scotland (Ed.), Reflections on assessment. Mansfield: Quality Assurance Agency, 2: 125-137. .

Zacharis, N.Z., 2010. Innovative assessment for learning enhancement: Issues and practices. Contemporary Issues in Education Research, 3(1): 61-70.Available at: https://doi.org/10.19030/cier.v3i1.162.

Zou, P.X., 2008. Designing effective assessment in postgraduate construction project management studies. Journal for Education in the Built Environment, 3(1): 80-94.Available at: https://doi.org/10.11120/jebe.2008.03010080. 